\title{
Ultraflexible organic electronics
}

\author{
Takao Someya, Martin Kaltenbrunner, and Tomoyuki Yokota
}

In this article, we review recent research progress on ultraflexible organic thin-film devices and their emerging applications. We describe progress on devices such as organic thinfilm transistors, organic photovoltaic cells, and organic light-emitting diodes that are manufactured on ultrathin plastic films with micrometer-scale thicknesses. These ultraflexible organic devices have been utilized to realize new applications, including wearable and biomedical devices.

\section{Introduction}

Flexible electronic devices ${ }^{1-4}$ are expected to open a range of new applications, including flexible displays, ${ }^{5-9}$ flexible radio frequency (RF) identification devices, ${ }^{10-15}$ chemical sensors, ${ }^{16-18}$ flexible large-area physical sensors, ${ }^{19-23}$ and actuators. ${ }^{24-27}$ One promising application of flexible electronics that has been attracting attention is sensors for the continuous monitoring of bioinformation, such as pulse $\mathrm{e}^{28-30}$ and body temperature..$^{31-35}$ Such sensor devices would be used in direct contact with human skin and should thus be mechanically flexible such that they are imperceptible; in terms of hygiene, they should also be easily and safely disposable, unlike conventional electronic components.

Organic semiconductors are suitable for flexible electronics, yet they are not unique solutions. Another attractive approach is to utilize ultrathin silicon because it exhibits high electronic performance with mechanical flexibility. ${ }^{36-38}$ Using this approach, Rogers and co-workers demonstrated epidermal electronics ${ }^{36}$ that can be directly laminated on the surface of human skin to introduce electronic functionalities.

However, directly manufacturing sensors or electronic circuits on ultrathin polymeric films with thicknesses of several micrometers or less is a difficult task using conventional semiconductor processes. As discussed in detail later, a reduction in the total thickness of the devices can improve their mechanical flexibility. ${ }^{39}$ Therefore, new materials, processes, and device structures have to be explored. Organic thin-film devices are expected to yield simultaneously large-area, lowcost, lightweight, and flexible devices because they can easily be fabricated on polymer films by printing processes such as inkjet printing. ${ }^{44-48}$

In this article, we review recent progress on large-area, ultraflexible, and stretchable organic electronics and related technologies. In particular, ultraflexible organic thin-film devices such as organic thin-film transistors (OTFTs), ${ }^{49-53}$ organic photovoltaic (OPV) cells, ${ }^{54}$ and organic light-emitting diodes (OLEDs) $)^{55,56}$ are described. Next, emerging applications using flexible organic devices are presented. Finally, other relevant issues and future prospects are described.

\section{Organic thin-film devices Device and process design to reduce strain}

Strain occurs whenever any device is bent, ${ }^{39,40}$ and all semiconductor devices show performance changes in response to strain or deformation. First, strain causes geometrical changes, that is, changes in device dimensions such as the channel length or width of a transistor or the thickness of an insulator film. Such geometrical changes cause modifications in the

Takao Someya, Department of Electric and Electronic Engineering, School of Engineering, The University of Tokyo, Japan; and Exploratory Research for Advanced Technology, Japan Science and Technology Agency, Japan; someya@ee.t.u-tokyo.ac.jp

Martin Kaltenbrunner, Soft Matter Physics Department, Johannes Kepler University, Austria; martin.kaltenbrunner@jku.at

Tomoyuki Yokota, Department of Electric and Electronic Engineering, School of Engineering, The University of Tokyo, Japan; and Exploratory Research for Advanced Technology, Japan Science and Technology Agency, Japan; yokota@ntech.t.u-tokyo.ac.jp

DOI: $10.1557 / \mathrm{mrs} .2015 .277$ 
device characteristics. For example, capacitance, expressed as $C=\kappa A / d$, changes when device dimensions $A$ and $d$ change, where $A, d$, and $\kappa$ represent the capacitor area, insulator thickness, and dielectric constant, respectively. The properties of semiconductors and insulators, such as mobility and dielectric constant, are also sensitive to strain. Moreover, when the strain exceeds the limit of plastic deformation, a device will be irreversibly degraded or destroyed by rupture or delamination. The conventional engineering solution to avoid these problems is to reduce the thickness of the whole device.

The surface strain upon bending a film can be described by the equation $\varepsilon=d /(2 R)$, where $\varepsilon, d$, and $R$ are the surface strain, the thickness of the film, and the bending radius, respectively. ${ }^{39,40}$ The channel layers and electrodes in OTFTs are typically $50 \mathrm{~nm}$ thick, whereas the gate dielectric layers range in thickness from a few nanometers to $500 \mathrm{~nm}$; as a result, the total thickness of the device layers can remain less than $1 \mu \mathrm{m}$. The total thickness of a device module is usually determined by the thickness of the substrate; thus, reducing the substrate thickness is an effective way to diminish strain.

Theoretically, no strain is induced at the exact center of the film along the thickness direction when the film is bent. This center is referred to as the neutral-strain or neutral-plane position. In principle, a device could be placed at the neutralstrain position by precisely controlling the thickness of the surrounding layers. However, because the actual thickness of a device is greater than zero, some parts of the device layers slip slightly from the neutral-strain position, causing performance changes due to the strain.

Fabricating device structures with designs that suppress strain effects is challenging for the following reasons: (1) Thinner substrates are easily deformed because of tension or other handling constraints, which makes their handling difficult. Typically, a thin base film is mounted on a glass substrate during device fabrication and then peeled off from the glass when the fabrication is completed. However, the processes of lamination and delamination are delicate. (2) Thin substrates have a tendency to shrink during device fabrication. Lowering process temperature compared to the corresponding processes with thick films is therefore imperative. In particular, the difference in the thermal expansion coefficient of each layer causes curling of films or cracks after high-temperature processing. (3) The surface of plastic films is usually not smooth enough for the direct fabrication of high-performance devices. Indeed, the surfaces of commercial films are intentionally roughened to reduce adhesion during roll-to-roll processing. This roughness can be reduced by coating the film with a surface planarization layer, but this increases the thickness. (4) High-energy processes such as plasma processing interfere with the flat surface of films, so such steps must be minimized. (5) A device usually consists of layers of several different materials. It is quite difficult to analyze or model failure modes because of differences in mechanical properties or adhesion of each of these materials.
Research has resolved these issues and has significantly improved the mechanical durability of flexible organic devices. Next, we review some of these efforts.

\section{Ultrathin organic transistors}

Many OTFTs used to be made on rigid substrates or thick (typically several tens of micrometers) plastic films; however, Sekitani et al. manufactured OTFTs on a $12.5-\mu \mathrm{m}$-thick polyimide film, which is widely used in flexible circuit boards. ${ }^{57}$ Because the surface of commercial polyimide is not sufficiently smooth, it was coated with polyimide precursors and crosslinked at $180^{\circ} \mathrm{C}$ to form a 0.5 - $\mu \mathrm{m}$-thick surface planarization layer. The surface roughness of the planarization layer was $0.3 \mathrm{~nm}$ rms, similar to that of silicon dioxide layers grown thermally on carefully polished single-crystalline silicon wafers. On this planarization layer, the researchers then sequentially formed 20-nm-thick aluminum gate electrodes, a 6-nm-thick hybrid dielectric of aluminum oxide $\left(\mathrm{AlO}_{x}\right)$ and an organic self-assembled monolayer (SAM), ${ }^{58,59}$ 30-nm-thick semiconductor layers, and 50-nm-thick gold source/drain contacts. The total thickness of the TFT was only $106 \mathrm{~nm}$. After fabrication of the OTFTs, the film was coated with a $13-\mu$ m-thick parylene encapsulation layer so that the device layers were in the neutral-strain position. The hole mobility and on/off ratio of these OTFTs were $1.2 \mathrm{~cm}^{2} /(\mathrm{V} \mathrm{s})$ and $10^{6}$, respectively. The films tolerated a minimum bending radius of $100 \mu \mathrm{m}$ without any mechanical or electric degradation of the devices.

Further improvements in the properties of the OTFTs can be expected by reducing the thickness of substrates. In one case, OTFTs were manufactured on 1.2- $\mu$ m-thick poly(ethylene naphthalate) (PEN) films. ${ }^{49}$ The weight of the finished device was $3 \mathrm{~g} / \mathrm{m}^{2}$, or about $1 / 30$ th that of standardweight office paper, and the total thickness was $2 \mu \mathrm{m}$, which is about $1 / 5$ th that of plastic kitchen wrap. This was possible because of a novel technique to form a high-quality 19-nmthick insulating layer on the rough surface of the 1.2- $\mu$ m-thick polymeric film. ${ }^{10}$ Aluminum gate layers were deposited on the base film using a vacuum system. The gate-dielectric layers comprised anodic aluminum oxide and a phosphonic acid SAM. ${ }^{58,59}$ A 30-nm-thick layer of the air-stable organic semi-

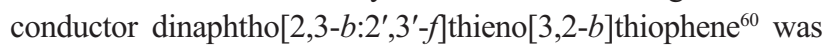
deposited by vacuum evaporation. Finally, gold layers were deposited by vacuum evaporation as source/drain electrodes. The channel length and width were $40 \mu \mathrm{m}$ and $500 \mu \mathrm{m}$, respectively. The transistors exhibited a saturation hole mobility of $3 \mathrm{~cm}^{2} /(\mathrm{V} \mathrm{s})$.

The organic-transistor $p$-type metal-oxide-semiconductor integrated circuits (ICs) exhibited extraordinary robustness even though they were $2 \mu \mathrm{m}$ thick. Indeed, the electrical properties and mechanical performance of the ICs were practically unchanged, even when squeezed to reduce the bending radius to $5 \mu \mathrm{m}$, crumpled like paper, or dropped from a height of $1 \mathrm{~m}$. Furthermore, amazing durability was demonstrated: After the ICs had been immersed for more than two weeks in physiological saline (with components that are the same as 
bodily fluids or sweat), no obvious deterioration in the electrical properties was observed.

\section{From ultraflexible to stretchable organic transistors} One of the unique features of transistors manufactured on $1-\mu \mathrm{m}$-thick substrates is their applicability to stretchable electronics: ${ }^{42,61-63}$ Stretchability is needed to adapt to surfaces that have non-zero Gaussian curvature. After fabrication of the devices, the electronic film containing them is laminated onto a prestretched elastomer by simple picking and placing. When the strain in the elastomer is allowed to relax, adhesion between the elastomer and the thin electronic foil transfers the strain to the foil. The resulting network of out-of-plane wrinkles accommodates subsequent tensile strain, which enables stretching of the device in the direction of the initial deformation of the elastomer. ${ }^{49}$

To determine the minimum bending radii of the multiple folds that form in the active area of the transistors, we analyzed cross-sectional scanning electron microscopy images of a transistor undergoing 233\% tensile strain. Despite the extreme bending conditions, not only did the transistors remain fully functional, but, because of the neutral-plane fabrication, there was virtually no degradation in performance. We observed neither irreversible degradation nor an increase in gate leakage current during the stretching experiment.

\section{Mechanically adaptive electronics}

Ultrathin OTFTs can be combined with shape-memory polymers (SMPs) ${ }^{64}$ to realize mechanically adaptive electronics. ${ }^{65}$ For this application, OTFTs are coated with a SMP layer. The SMP layer can be partially polymerized; deformed into a complex three-dimensional (3D) shape; and then fully cured, allowing for the fabrication of 3D electronics.

In one example, Reeder et al. coated OTFTs with a $100-\mu \mathrm{m}$-thick SMP layer using a transfer-by-polymerization process. ${ }^{65}$ Partially polymerized SMP films continue to polymerize at a low rate even after removal from UV exposure through the thermally induced reaction of unreacted functional groups at room temperature. For this reason, the OTFTs for mechanically adaptive devices were fabricated on a separate 1.4- $\mu \mathrm{m}$-thick poly(ethylene terephthalate) (PET) layer and encapsulated with parylene before being coated with SMP, thus minimizing the time between the partial polymerization of the SMP and the reshaping of the device into a helix. These encapsulated devices were then used for acute in vitro stability tests. The adaptive OTFTs were conformed in vivo using only physiological conditions to trigger softening of the substrate.

\section{Organic electrochemical transistors}

In addition to organic thin-film transistors, organic electrochemical transistors (OECTs $)^{51-53}$ have also been developed. Because OECTs are very sensitive to potential fluctuations induced by ions, such as electrophysiological signals, they have attracted much attention as flexible neural interfaces.
For example, Malliaras and co-workers manufactured OECTs on ultrathin films for in vivo measurements of auditory responses in a rat's brain. ${ }^{51}$ These OECTs had a channel layer consisting of the conducting polymer poly(3,4-ethylenedioxythiophene) doped with poly(styrene sulfonate) (PEDOT:PSS), in direct contact with an electrolyte. Malliaras and co-workers formed OECTs on 2- $\mu \mathrm{m}$-thick parylene with very large transconductance in the millisiemens range..$^{51}$

The operating speed of OECTs is inversely proportional to the total volume of the active layer, so both the channel length and width were reduced to $10 \mu \mathrm{m}$. This device exhibited constant DC transconductance up to a frequency on the order of $1 \mathrm{kHz}$, which is high enough to detect signals from neurons without deforming the waveforms. The total thickness, including substrate and encapsulation layers, was as small as $4 \mu \mathrm{m}$. Because of this very small thickness, the device did not experience mechanical failure even when crumpled. Making full use of mechanical conformability, the device was directly applied to the surface of a rat's brain as an electrocochleography probe and exhibited better signal-to-noise ratio than surface electrodes due to local amplification.

\section{Printed organic transistors}

In addition to organic transistors manufactured by vacuum deposition and photolithography, as described so far, organic transistors have been manufactured by printing on ultrathin films for low-cost, wearable electronic applications. For example, Tokito and co-workers fabricated $p$-channel organic transistors and inverter circuits using only printing processes on $1-\mu \mathrm{m}$-thick polymeric films. ${ }^{50}$ The parylene films were deposited on glass plates by chemical vapor deposition. The surface of the parylene was coated with a 130-nm cross-linked poly(vinylpyridine) (PVP) layer for reduced surface roughness $(0.18 \mathrm{~nm} \mathrm{rms})$. The surface of the PVP layer was treated in an oxygen plasma to improve wettability. The control of surface smoothness and wettability is very important for forming multifunctional layers by printing. The OTFTs were formed by inkjet printing and removed from the glass plates after fabrication. The printed OTFTs exhibited a hole mobility of $1.0 \mathrm{~cm}^{2} /(\mathrm{V} \mathrm{s})$ at an operating voltage of $10 \mathrm{~V}$ and on/off ratios exceeding $10^{6}$. Printed OTFTs are expected to enable cheap and environmentally friendly large-area circuits for novel wearable applications.

\section{Ultrathin organic solar cells}

OPV cells ${ }^{54}$ are highly promising devices for solar energy generation. Primary benefits of OPV cells are low cost, low weight, flexibility, and compatibility with reel-to-reel processing for high-volume production. These organic solar cells can be fabricated on ultrathin substrates without degrading the power-conversion efficiency as compared to that of their glass-substrate counterparts. ${ }^{54}$

We have developed a method for fabricating ultrathin, lightweight, flexible, and compliant OPV devices on only 1.4- $\mu \mathrm{m}$-thick PET substrates (see Figure 1). We obtained solar cells with a $4.2 \%$ power-conversion efficiency that 


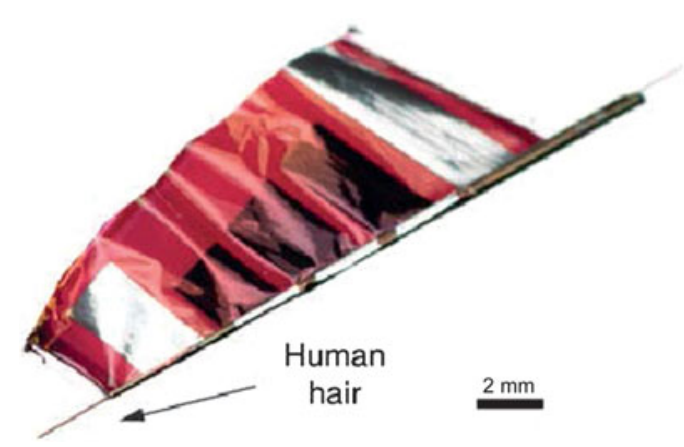

Figure 1. This ultrathin organic photovoltaic device is the thinnest ever fabricated. Reproduced with permission from Reference 54. (C) 2012 Nature Publishing Group.

weighed as little as $4 \mathrm{~g} / \mathrm{m}^{2}$. This resulted in an unprecedented specific power of $10 \mathrm{~W} / \mathrm{g}$, the highest value achieved for all solar cell technologies at that date. The extremely low weight and high specific power output are advantageous for mobile applications, such as power supplies for stress-free healthcare devices or remote sensing applications. ${ }^{54}$ The high flexibility of these devices allows them to be wrapped around a human hair and to reversibly attain a tensile strain of more than $300 \%$ when placed on an elastomeric support.

\section{Ultraflexible OLEDs}

Recently, the use of OLEDs for displays and lighting has become commonplace (see Figure 2). OLED displays can be superior to conventional liquid-crystal displays (LCDs) in terms of power consumption, color reproducibility, and response speed; as a result, they are replacing LCDs in numerous applications. Nevertheless, further reductions in weight and thickness are still desirable. We have demonstrated ${ }^{55}$ a technique for forming organic semiconductor materials on an ultrathin 1.4- $\mu \mathrm{m}$-thick polymeric film. We succeeded in developing the world's lightest $\left(3 \mathrm{~g} / \mathrm{m}^{2}\right)$ and, simultaneously, the world's thinnest $(2 \mu \mathrm{m})$ mechanically flexible ultrathin polymer OLEDs with this technology. ${ }^{55}$

The key to this success is low-temperature processing that enables OLEDs to be fabricated on a rough $1-\mu \mathrm{m}$-thick polymeric film without impairing their mechanical properties.
Instead of using an indium tin oxide transparent electrode that requires high-temperature and high-energy processing, we employed a conductive polymer, PEDOT:PSS, that can be fabricated at low temperatures.

These ultrathin OLEDs allowed crumpling during device operation (see Figure 2). They were found to be extremely flexible, with radii of curvature under $10 \mu \mathrm{m}$, with an operating display luminance of $100 \mathrm{~cd} / \mathrm{m}^{2}$. These OLEDs were as flexible as rubber when placed on soft and stretchable elastomers. ${ }^{55}$ We expect that these soft, ultrathin, and ultralight OLEDs will be very useful in various fields: For instance, they could become OLED lighting fixtures that can be applied to almost any surface for ultraflexible OLED displays and as light sources for imperceptible healthcare sensors.

\section{Integrated circuits and systems on foils Design}

A practical system design for a specific application can require a combination of different types of electronic components such as processors, amplifiers, communication systems, batteries, memory, sensors, and displays. When more types of components become available, higher performance and more opportunities can be expected. This means that flexible largearea systems cannot be developed if only one component is mechanically flexible. Because different flexible components are still being developed, system design requires a combination of existing rigid parts as well as newly developed flexible parts.

When mechanical durability varies for different components, it is desirable to place mechanically fragile components in less bendable locations. Such techniques are commonly used in flexible circuit boards. Indeed, in flexible printed circuit boards (FPCBs), pliable elements such as metal wiring are formed on flexible polyimide film, whereas the rigid chip is placed on the stiff parts of the FPCBs. Similarly, it is effective to locally change the stiffness of a flexible substrate for a flexible device system and carefully choose the position of each component, depending on its mechanical durability.

A fundamental question that arises is which component should be mechanically flexible to design flexible systems. The answer is not straightforward and depends on the application. It is clear that components that are placed directly on

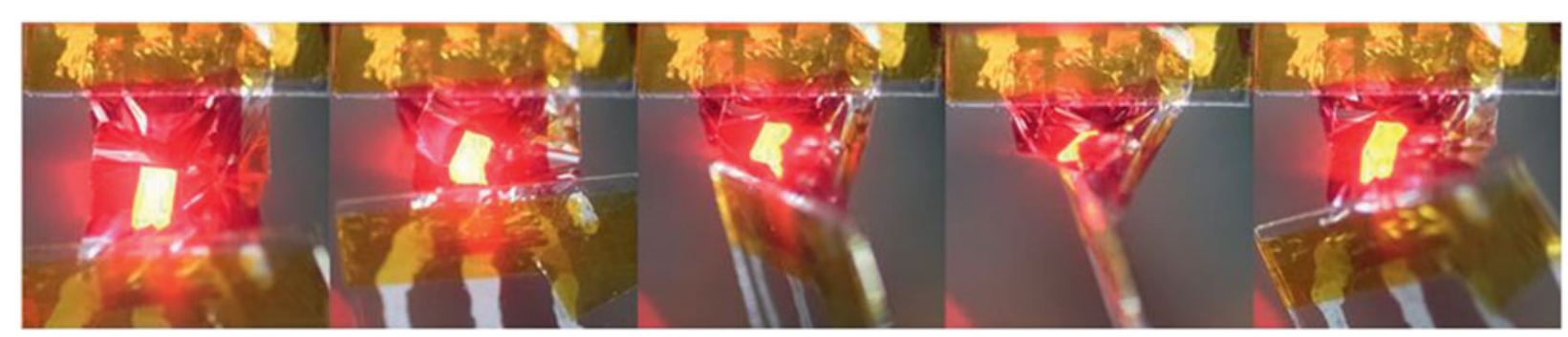

Figure 2. Organic light-emitting diodes (OLEDs) manufactured on a 1- $\mu \mathrm{m}$-thick polymeric substrate. The OLEDs continue operating even when subjected to extreme deformation (crumpling, in this case). Reproduced with permission from Reference 55 . (C) 2013 Nature Publishing Group. 
curved surfaces must be flexible, and this category includes displays and sensors. For this reason, the research and development of flexible electronics began with displays and sensors and has gradually expanded to more advanced elements such as processors and wireless radio circuits.

To design such a flexible system, it is important to pay attention to the compatibility of all elements, in terms of both their processing requirements and their electrical performance.

One of the unique features of flexible devices is the possibility to integrate multiple functions simply by lamination. Specifically, display units, driving circuits, sensors, and other components can be separately manufactured on different films and then laminated together. The advantage of this approach is that the compatibility of the processes for manufacturing each sheet need not be considered.

It is also important to address the following disadvantages of lamination: First, the ease of bending can be impaired because the total thickness is increased. Second, when the sheets are not electrically independent, electrical connections between the sheets are needed. Because a flexible sheet has limited dimensional stability, it is difficult to realize large numbers of electrical connections. It is even harder to ensure the reliability of these contacts when the device is bent during use.

In contrast, integration of all of the components on a single film requires process compatibility during production. However, the reduced total thickness of the system improves its mechanical durability.

Once the processes are chosen and the system is designed, the electrical characteristics of each component can be roughly estimated. However, when elements are integrated, interlayer films can prevent an integrated device from realizing the properties achieved in isolation. It is also not unusual for the characteristics of displays or other devices that undergo complicated processes to degrade. For example, the mobility of a transistor can be degraded by an order of magnitude.

For system design, it is necessary to ensure that these potentially degraded electrical properties of integrated devices still meet the specifications. For display applications, for example, these specifications depend on the display media such as light emitters. Improving the performance of transistors in driving circuits makes more reliable design possible and allows the operating frame rates to be increased.

Recently, various types of flexible components have been reported. With flexible and stretchable batteries, ${ }^{66-70}$ processors, ${ }^{71}$ and memory ${ }^{72-77}$ becoming available, more complex devices with good electrical properties can be achieved using only flexible devices, enabling entire systems with mechanical flexibility throughout.

\section{Flexible displays}

Flexible displays have been a key driver of the development of flexible electronics, and they continue to inspire lighter and thinner devices. ${ }^{5-9}$ Flexible devices have been used for these displays to improve integration, uniformity, reliability, and electrical performance. Such devices, fabricated on plastics, achieve the better durability needed for mobile electronics or wearable electronics, and bendable displays allow the design of uniquely shaped products. Because they showcase cuttingedge devices, the performance of flexible displays plays a benchmark role even for other applications.

The leading candidates for flexible displays are OLEDs for self-emission applications and electrophoretic displays for passive, electronic-paper applications. Many excellent books and reviews on flexible displays are available, ${ }^{5-9,78}$ so here, we briefly describe a few recent achievements in this area.

High-definition, full-color, active-matrix flexible OLED displays ${ }^{79,80}$ have been commercialized. Thin polyimide films are coated onto glass plates, on which OLED displays based on low-temperature polycrystalline silicon are manufactured. The polyimide bearing the devices is removed from the glass plates after fabrication. Such flexible OLEDs can be permanently applied to the curved surfaces of the corners of smart phones, for example. Furthermore, Sony reported 4.1-in. rollable full-color organic displays with a resolution of $121 \mathrm{ppi}$ formed on $80-\mu \mathrm{m}$-thick films. Movies can be shown on these displays even after they have been rolled repeatedly to a radius of $4 \mathrm{~mm}$.

Reduction in the manufacturing costs of flexible displays is very important. In this context, the manufacturing of flexible devices using printing processes has attracted much attention. Ricoh has reported all-printed flexible displays with a resolution of 200 ppi, ${ }^{81}$ and Toppan Printing has realized all-printed electrophoretic flexible displays for use in price tags. ${ }^{82}$

\section{Flexible sensors}

Various types of flexible sensors have been manufactured on flexible substrates. Although both chemical and physical sensors are available, we focus here on physical sensors, such as pressure, strain, thermal, and magnetic sensors. As for conventional sensors on rigid substrates, it is important that flexible sensors meet requirements of reproducibility, reversibility, and sensitivity. Characteristics of linearity, dynamic range, and response time are also crucial. Additionally, flexible sensors have the challenge of minimizing motion artifacts, that is, changes in sensing properties induced by deformation, a problem not found in rigid sensors.

Many groups have reported flexible pressure sensors. For example, Bao and co-workers reported ultrahigh-sensitivity pressure sensors. ${ }^{28}$ They fabricated novel pyramid-shaped elastomers by molding and used these elastomers as the gate dielectric layers of organic transistors. A pressure sensitivity of over $30 \mathrm{~Pa}$ was achieved. The flexible sensors could be directly attached to the wrist, for example, to monitor pulse rate.

Electronic artificial skin (e-skin) is one promising application for flexible pressure sensors. To realize multipoint detection, one of the major issues is the vast extent of wiring required for data readout. Indeed, human skin consists of millions of pain points. Tactile sensors for robots are usually assembled with discrete devices, each with individual wiring; thus, the number of pressure sensors in the case of robots is 
limited and far less than the density of sensory receptors in human skin. To increase the number of sensor cells and to realize scalable design schemes, active data readout is an ideal solution. Toward this end, an active-matrix $16 \times 16$ pressure sensor matrix was demonstrated. ${ }^{19,20}$ A similar design was also applied in photodetectors ${ }^{83}$ and other applications to realize multipoint detection with different sensing functions. ${ }^{84}$

\section{Biosignal detection}

Whereas robotic skin is targeted toward machine applications, sensor applications for constant monitoring of bioinformation, such as pulse rate and body temperature, have been attracting attention. Because such sensor devices would be used in direct contact with human skin (see Figure 3), they need to be flexible, imperceptible, and capable of wireless data transmission.

As one of the emerging applications of ultrathin organic devices, a 64-channel surface electromyogram (EMG) measurement sheet was manufactured for prosthetic hand control. ${ }^{85}$ Because the signals of interest are very small, their reliable readout usually requires amplifiers. To place amplifiers as close to the signal source as possible, flexible amplifiers are needed. A distributed and shared amplifier architecture, based on 2-V organic transistors on an ultraflexible PEN film, enabled in situ amplification of the myoelectric signal with a factor-of-4 increase in EMG electrode density. A postfabrication selectand-connect method reduced the transistor mismatch and the power by $92 \%$ and $56 \%$, respectively, compared with those of conventional parallel transistors.

In addition to electric signals, light sensing also plays an important role in wearable electronics. Some commercial watch-type wearables already contain pulse monitors with rigid photonic sensors, but it will be advantageous to replace them with ultrathin organic devices. In this context, Arias and

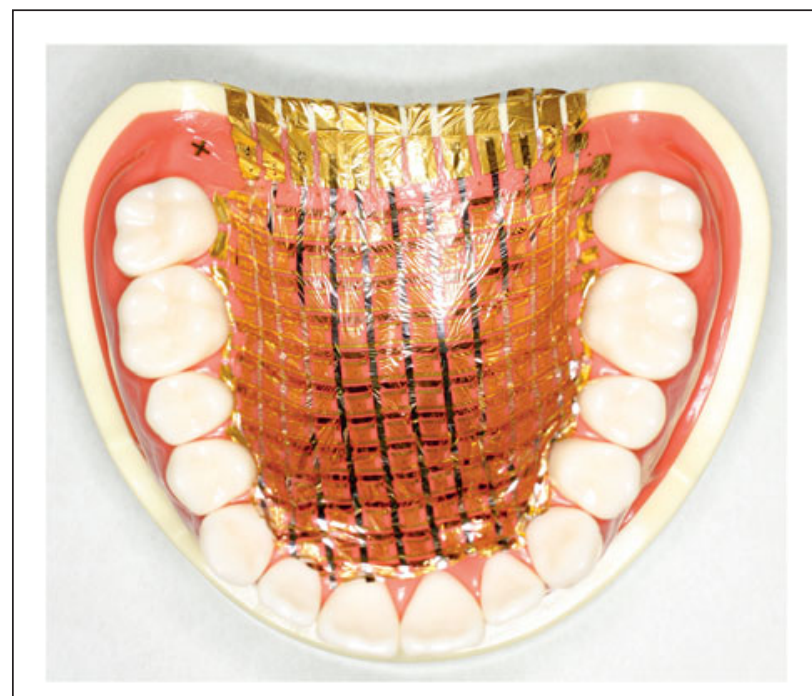

Figure 3. Organic thin-film transistors manufactured on a $1-\mu \mathrm{m}$-thick polymeric substrate are able to tightly conform to a model of the human upper jaw. ${ }^{50}$ Reproduced with permission from Reference 49. (C) 2013 Nature Publishing Group. co-workers have developed an all-organic pulse monitor with combined OLEDs and an organic photodetector. ${ }^{29}$ Although the device was separately manufactured on glass and assembled afterward, it demonstrates the promise of organic photonic sensors.

\section{System integration}

The availability of diverse and functional components for flexible electronics allows the design of increasingly complex systems. One recent example is a flexible fever-alarm armband that generates electricity from indoor illumination and produces a sound upon the detection of fever. The armband includes an organic IC, a temperature detector, flexible solar cells, and a piezoelectric film speaker. ${ }^{86}$ The temperature detector and organic IC are fabricated on a polymer film. Because the operation is powered by electricity generated from indoor illumination, the changing of batteries is not required.

This flexible fever-alarm armband has three notable features. The first is an adjustable detection temperature, which was realized using a newly developed variable-resistance temperature detector formed on a flexible polymer film. ${ }^{86}$ The second is a flexible electronic buzzer comprising an organic IC and a piezoelectric film speaker. To our knowledge, this was the first report of sound generated using an organic IC. The third is a power-supply circuit that enables the use of the flexible fever-alarm armband in rooms with illumination at various light intensities. This device also represents the first known demonstration to realize a power-supply circuit consisting of organic transistors alone. The principles of this research are expected to be applicable to a wide variety of fields. Specifically, the design can accommodate other sensors, such as those for moisture or pressure in addition to temperature, suggesting interesting possibilities for the future.

\section{Summary and future prospects}

Recent progress in organic large-area flexible electronics has been described in this article. We have focused on the development of organic devices manufactured on ultrathin polymeric films with thicknesses of $1.2 \mu \mathrm{m}$ or $1.4 \mu \mathrm{m}$. As the total thickness is reduced, one can expect both reductions in weight and improvements in mechanical flexibility, yielding excellent conformability. Indeed, organic devices have been directly attached to the surfaces of complicated 3D objects, such as the human upper jaw (see Figure 3), as well as those of moving objects, such as a living, beating heart. Thanks to recent intensive research efforts, both the electronic performance and the mechanical durability of ultrathin organic devices have improved significantly.

For new applications of ultraflexible organic devices, some issues need to be solved in the near future. One critical issue is the environmental stability of organic devices. On rigid substrates, organic devices have high reliability thanks to good encapsulation technologies. For devices on ultrathin films, however, such technologies are usually either incompatible 
or perform poorly. For this reason, it is important to develop good encapsulation layers that are compatible with ultrathin films. Simultaneously, it is important to improve the environmental stability of organic devices themselves by developing air-stable organic semiconductors.

Another issue is the need to establish reliable interfaces between ultraflexible and rigid/semirigid devices. As discussed with regard to system design, multiple electronic components are needed to build sophisticated electronic systems. It is clear that flexible systems have to be combined with conventional silicon-based components that would be responsible at least for signal processing and wireless data transmission. However, mechanically connecting rigid and ultraflexible devices is not a trivial issue. Indeed, when hybrid systems combining rigid and flexible components are bent, large strains are induced locally at points where the material stiffness changes. Ways to gradually change material stiffness would be effective in minimizing the risk of strain-induced mechanical failures. ${ }^{87-90}$

The last issue is the importance of developing flexible passive elements that are compatible with processes used on ultrathin films. Circuits for wireless data transmission and power transmission need inductive or capacitive elements. In addition, amplifiers and other analog circuits need highperformance and high-precision passive elements. The ultimate performance of passive elements is limited by the material properties themselves, such as conductivity and dielectric constant. However, it is difficult to obtain good performance on ultrathin films because all of the elements are fabricated by room-temperature processes, which can differ from the optimized high-temperature processes. The development of new materials and processes that exhibit high conductivity and high dielectric constants at room temperature is key to further advancing the frontiers of ultraflexible devices that will play an important role in wearable and implantable electronics.

\section{Acknowledgments}

The authors thank Tsuyoshi Sekitani of Osaka University; Takayasu Sakurai, Makoto Takamiya, and Masaki Sekino of the University of Tokyo; and Niyazi Serdar Sariciftci, Siegfried Bauer, Matthew S. White, and Ingrid Graz of Johannes Kepler Universität (Linz, Austria) for fruitful collaborations and discussions.

\section{References}

1. W.S. Wong, A. Salleo, Eds., Flexible Electronics: Materials and Applications (Springer, New York, 2009).

2. H. Klauk, Ed., Organic Electronics: Materials, Manufacturing, and Applications (Wiley-VCH, Weinheim, Germany, 2006).

3. H. Klauk, Ed., Organic Electronics II: More Materials and Applications (Wiley-VCH, Weinheim, Germany, 2012).

4. S.-W. Hwang, G. Park, H. Cheng, J.-K. Song, S.-K. Kang, L. Yin, J.-H. Kim, F.G. Omenetto, Y. Huang, K.-M. Lee, J.A. Rogers, Adv. Mater. 26, 1992 (2014). 5. G. Crawford, Ed., Flexible Flat Panel Displays (Wiley, Chichester, UK, 2005). 6. G.H. Gelinck, H.E.A. Huitema, E. van Veenendaal, E. Cantatore, L. Schrijnemakers, J.B.P.H. van der Putten, T.C.T. Geuns, M. Beenhakkers, J.B. Giesbers, B.-H. Huisman, E.J. Meijer, E. Mena Benito, F.J. Touwslager, A.W. Marsman, B.J.E. van Rens, D.M. de Leeuw, Nat. Mater. 3, 106 (2004).
7. M. Noda, N. Kobayashi, M. Katsuhara, A. Yumoto, S. Ushikura, R. Yasuda, N. Hirai, G. Yukawa, I. Yagi, K. Nomoto, T. Urabe, J. Soc. Inf. Disp. 19 (4), 316 (2011).

8. J.A. Rogers, Z. Bao, K. Baldwin, A. Dodabalapur, B. Crone, V.R. Raju, V. Kuck, H. Katz, K. Amundson, J. Ewing, P. Drzaic, Proc. Natl. Acad. Sci. U.S.A. 98 (9), 4835 (2001)

9. P. Andersson, D. Nilsson, P.-0. Svensson, M. Chen, A. Malmström, T. Remonen, T. Kugler, M. Berggren, Adv. Mater. 14, 1460 (2002).

10. P.F. Baude, D.A. Ender, M.A. Haase, T.W. Kelley, D.V. Muyres, S.D. Theiss, Appl. Phys. Lett. 82, 3964 (2003).

11. S. Steudel, K. Myny, V. Arkhipov, C. Deibel, S. De Vusser, J. Genoe, P. Heremans, Nat. Mater. 4, 597 (2005).

12. S. Steudel, S. De Vusser, K. Myny, M. Lenes, J. Genoe, P. Heremans, J. Appl. Phys. 99, 114519 (2006).

13. E. Cantatore, T.C.T. Geuns, G.H. Gelinck, E. van Veenendaal, A.F.A. Gruijthuijsen, L. Schrijnemakers, S. Drews, D.M. de Leeuw, IEEE J. Solid-State Circuits 42, 84 (2007).

14. V. Subramanian, J.M.J. Frechet, P.C. Chang, D.C. Huang, J.B. Lee, S.E. Molesa A.R. Murphy, D.R. Redinger, S.K. Volkman, Proc. IEEE 93, 1330 (2005).

15. M. Jung, J. Kim, J. Noh, N. Lim, C. Lim, G. Lee, J. Kim, H. Kang, K. Jung, A.D. Leonard, J.M. Tour, G. Cho, IEEE Trans. Electron Devices 57, 571 (2010).

16. O. Knopfmacher, M.L. Hammock, A.L. Appleton, G. Schwartz, J. Mei, T. Lei, J. Pei, Z. Bao, Nat. Commun. 5, 2954 (2014).

17. M.Y. Mulla, E. Tuccori, M. Magliulo, G. Lattanzi, G. Palazzo, K. Persaud, L. Torsi, Nat. Commun. 6, 6010 (2015).

18. J.T. Mabeck, G.G. Malliaras, Anal. Bioanal. Chem. 384 (2), 343 (2006)

19. T. Someya, T. Sekitani, S. Iba, Y. Kato, H. Kawaguchi, T. Sakurai, Proc. Natl. Acad. Sci. U.S.A. 101, 9966 (2004).

20. T. Someya, Y. Kato, T. Sekitani, S. Iba, Y. Noguchi, Y. Murase, H. Kawaguchi, T. Sakurai, Proc. Natl. Acad. Sci. U.S.A. 102 (35), 12321 (2005).

21. T. Sekitani, Y. Noguchi, K. Hata, T. Fukushima, T. Aida, T. Someya, Science 321, 1468 (2008).

22. T. Sekitani, H. Nakajima, H. Maeda, T. Fukushima, T. Aida, K. Hata, T. Someya, Nat. Mater. 8, 494 (2009)

23. T. Sekitani, T. Someya, Adv. Mater. 22, 2228 (2010).

24. M. Ma, L. Guo, D.G. Anderson, R. Langer, Science 339, 186 (2013).

25. Q. Zhao, J.W.C. Dunlop, X. Qiu, F. Huang, Z. Zhang, J. Heyda, J. Dzubiella, M. Antonietti, J. Yuan, Nat. Commun. 5, 4293 (2014).

26. Y. Kato, T. Sekitani, M. Takamiya, M. Doi, K. Asaka, T. Sakurai, T. Someya, IEEE Trans. Electron Devices 54 (2), 202 (2007).

27. T. Fukushima, K. Asaka, A. Kosaka, T. Aida, Angew. Chem. Int. Ed. 44 (16), 2410 (2005).

28. G. Schwartz, B.C.-K. Tee, J. Mei, A.L. Appleton, D.H. Kim, H. Wang, Z. Bao, Nat. Commun. 4, 1859 (2013).

29. C.M. Lochner, Y. Khan, A. Pierre, A.C. Arias, Nat. Commun. 5, 5745 (2014).

30. A.K. Bansal, S. Hou, O. Kulyk, E.M. Bowman, I.D.W. Samuel, Adv. Mater., published online December 9, 2014, http://dx.doi.org/10.1002/adma.201403560.

31. L. Xu, S.R. Gutbrod, A.P. Bonifas, Y. Su, M.S. Sulkin, N. Lu, H.-J. Chung, K.-I. Jang, Z. Liu, M. Ying, C. Lu, R.C. Webb, J.-S. Kim, J.I. Laughner, H. Cheng, Y. Liu, A. Ameen, J.-W. Jeong, G.-T. Kim, Y. Huang, I.R. Efimov, J.A. Rogers, Nat. Commun. 5, 3329 (2014).

32. L. Gao, Y. Zhang, V. Malyarchuk, L. Jia, K.-I. Jang, R.C. Webb, H. Fu, Y. Shi, G. Zhou, L. Shi, D. Shah, X. Huang, B. Xu, C. Yu, Y. Huang, J.A. Rogers, Nat. Commun. 5, 4938 (2014)

33. J. Jeon, H.-B.-R. Lee, Z. Bao, Adv. Mater. 25 (6), 850 (2013).

34. I.J. Park, C.-Y. Jeong, I.-T. Cho, J.-H. Lee, E.-S. Cho, S.J. Kwon, B. Kim, W.-S. Cheong, S.-H. Song, H.-I. Kwon, Semicond. Sci. Technol. 27, 105019 (2012).

35. R.C. Webb, A.P. Bonifas, A. Behnaz, Y. Zhang, K.J. Yu, H. Cheng, M. Shi, Z. Bian, Z. Liu, Y.-S. Kim, W.-H. Yeo, J.S. Park, J. Song, Y. Li, Y. Huang, A.M. Gorbach, J.A. Rogers, Nat. Mater. 12, 938 (2013).

36. D.-H. Kim, N. Lu, R. Ma, Y.-S. Kim, R.-H. Kim, S. Wang, J. Wu, S.M. Won, H. Tao, A. Islam, K.J. Yu, T.-I. Kim, R. Chowdhury, M. Ying, L. Xu, M. Li, H.-J. Chung, H. Keum, M. McCormick, P. Liu, Y.-W. Zhang, F.G. Omenetto, Y. Huang, T. Coleman, J.A. Rogers, Science 333, 838 (2011).

37. J. Viventi, D.-H. Kim, L. Vigeland, E.S. Frechette, J.A. Blanco, Y.-S. Kim A.E. Avrin, V.R. Tiruvadi, S.-W. Hwang, A.C. Vanleer, D.F. Wulsin, K. Davis, C.E. Gelber, L. Palmer, J. Van der Spiegel, J. Wu, J. Xiao, Y. Huang, D. Contreras, J.A. Rogers, B. Litt, Nat. Neurosci. 14, 1599 (2011).

38. S. Xu, Y. Zhang, L. Jia, K.E. Mathewson, K.-I. Jang, J. Kim, H. Fu, X. Huang, P. Chava, R. Wang, S. Bhole, L. Wang, Y.J. Na, Y. Guan, M. Flavin, Z. Han, Y. Huang, J.A. Rogers, Science 344, 70 (2014).

39. Z. Suo, E. Ma, H. Gleskova, S. Wagner, Appl. Phys. Lett. 74, 1177 (1999).

40. H. Gleskova, S. Wagner, Z. Suo, Appl. Phys. Lett. 75, 3011 (1999).

41. J.A. Rogers, T. Someya, Y. Huang, Science 327, 1603 (2010). 
42. T. Sekitani, Y. Kato, S. Iba, H. Shinaoka, T. Someya, T. Sakurai, S. Takagi, Appl. Phys. Lett. 86, 073511 (2005).

43. T. Sekitani, S. Iba, Y. Kato, Y. Noguchi, T. Someya, T. Sakurai, Appl. Phys. Lett. 87, 173502 (2005).

44. H. Sirringhaus, T. Kawase, R.H. Friend, T. Shimoda, M. Inbasekaran, W. Wu, E.P. Woo, Science 290 (5499), 2123 (2000).

45. A.C. Arias, S.E. Ready, R. Lujan, W.S. Wong, K.E. Paul, A. Salleo, M.L. Chabinyc, R. Apte, R.A. Street, Y. Wu, P. Liu, B. Ong, Appl. Phys. Lett. 85 (15), 3304 (2004).

46. Z. Bao, Y. Feng, A. Dodabalapur, V.R. Raju, A.J. Lovinger, Chem. Mater. 9 (6), 1299 (1997).

47. T. Sekitani, Y. Noguchi, U. Zschieschang, H. Klauk, T. Someya, Proc. Natl. Acad. Sci. U.S.A. 105 (13), 4976 (2008).

48. H. Yan, Z. Chen, Y. Zheng, C. Newman, J.R. Quinn, F. Dötz, M. Kastler, A. Facchetti, Nature 457, 679 (2009).

49. M. Kaltenbrunner, T. Sekitani, J. Reeder, T. Yokota, K. Kuribara, T. Tokuhara, M. Drack, R. Schwödiauer, I. Graz, S. Bauer-Gogonea, S. Bauer, T. Someya, Nature 499, 458 (2013)

50. K. Fukuda, Y. Takeda, Y. Yoshimura, R. Shiwaku, L.T. Tran, T. Sekine, M. Mizukami, D. Kumaki, S. Tokito, Nat. Commun. 5, 4147 (2014).

51. D. Khodagholy, J. Rivnay, M. Sessolo, M. Gurfinkel, P. Leleux, L.H. Jimison, E. Stavrinidou, T. Herve, S. Sanaur, R.M. Owens, G.G. Malliaras, Nat. Commun. 4, 2133 (2013)

52. D. Khodagholy, T. Doublet, P. Quilichini, M. Gurfinkel, P. Leleux, A. Ghestem, E. Ismailova, T. Hervé, S. Sanaur, C. Bernard, G.G. Malliaras, Nat. Commun. 4, 1575 (2013).

53. A. Campana, T. Cramer, D.T. Simon, M. Berggren, F. Biscarini, Adv. Mater. 26 (23), 3874 (2014)

54. M. Kaltenbrunner, M.S. White, E.D. Głowacki, T. Sekitani, T. Someya, N.S. Sariciftci, S. Bauer, Nat. Commun. 3, 770 (2012).

55. M.S. White, M. Kaltenbrunner, E.D. Głowacki, K. Gutnichenko, G. Kettlgruber, I. Graz, S. Aazou, C. Ulbricht, D.A.M. Egbe, M.C. Miron, Z. Major, M.C. Scharber, T. Sekitani, T. Someya, S. Bauer, N.S. Sariciftci, Nat. Photonics 7, 811 (2013). 56. J. Liang, L. Li, X. Niu, Z. Yu, Q. Pei, Nat. Photonics 7, 817 (2013).

57. T. Sekitani, U. Zschieschang, H. Klauk, T. Someya, Nat. Mater. 9, 1015 (2010).

58. H. Klauk, U. Zschieschang, J. Pflaum, M. Halik, Nature 445, 745 (2007).

59. M. Halik, H. Klauk, U. Zschieschang, G. Schmid, C. Dehm, M. Schütz, S. Maisch, F. Effenberger, M. Brunnbauer, F. Stellacci, Nature 431, 963 (2004).

60. T. Yamamoto, K. Takimiya, J. Am. Chem. Soc. 129 (8), 2224 (2007).

61. T. Someya, Ed., Stretchable Electronics (Wiley-VCH, Weinheim, Germany, 2012).

62. S. Wagner, S. Bauer, MRS Bull. 37, 207 (2012).

63. D.-Y. Khang, H. Jiang, Y. Huang, J.A. Rogers, Science 311, 208 (2006).

64. W. Voit, T. Ware, R.R. Dasari, P. Smith, L. Danz, D. Simon, S. Barlow, Adv. Funct. Mater. 20 (1), 162 (2010)

65. J. Reeder, M. Kaltenbrunner, T. Ware, D. Arreaga-Salas, A. Avendano-Bolivar, T. Yokota, Y. Inoue, M. Sekino, W. Voit, T. Sekitani, T. Someya, Adv. Mater. 26 (29), 4967 (2014).

66. T. Suga, H. Ohshiro, S. Sugita, K. Oyaizu, H. Nishide, Adv. Mater. 21 (16), 1627 (2009).

67. S. Xu, Y. Zhang, J. Cho, J. Lee, X. Huang, L. Jia, J.A. Fan, Y. Su, J. Su, H. Zhang, H. Cheng, B. Lu, C. Yu, C. Chuang, T.-I. Kim, T. Song, K. Shigeta, S. Kang, C. Dagdeviren, I. Petrov, P.V. Braun, Y. Huang, U. Paik, J.A. Rogers, Nat. Commun. 4, 1543 (2012).

68. L. Hu, J.W. Choi, Y. Yang, S. Jeong, F. La Mantia, L.-F. Cui, Y. Cui, Proc. Natl. Acad. Sci. U.S.A. 106, 21490 (2009).

69. L. Hu, H. Wu, F. La Mantia, Y. Yang, Y. Cui, ACS Nano 4, 5843 (2010).

70. V.L. Pushparaj, M.M. Shaijumon, A. Kumar, S. Murugesan, L. Ci, R. Vajtai, R.J. Linhardt, O. Nalamasu, P.M. Ajayan, Proc. Natl. Acad. Sci. U.S.A. 104 13574 (2007)

71. K. Myny, E. van Veenendaal, G.H. Gelinck, J. Genoe, W. Dehaene, P. Heremans, IEEE J. Solid-State Circuits 47 (1), 284 (2012).

72. R.C.G. Naber, C. Tanase, P.W.M. Blom, G.H. Gelinck, A.W. Marsman, F.J. Touwslager, S. Setayesh, D.M. de Leeuw, Nat. Mater. 4, 243 (2005).

73. T. Sekitani, T. Yokota, U. Zschieschang, H. Klauk, S. Bauer, K. Takeuchi, M. Takamiya, T. Sakurai, T. Someya, Science 326 (5959), 1516 (2009).

74. K. Fukuda, T. Sekitani, U. Zschieschang, H. Klauk, K. Kuribara, T. Yokota, T. Sugino, K. Asaka, M. Ikeda, H. Kuwabara, T. Yamamoto, K. Takimiya, T. Fukushima, T. Aida, M. Takamiya, T. Sakurai, T. Someya, Adv. Funct. Mater. 21 (21), 4019 (2011).

75. R.H. Kim, H.J. Kim, I. Bae, S.K. Hwang, D.B. Velusamy, S.M. Cho, K. Takaishi, T. Muto, D. Hashizume, M. Uchiyama, P. André, F. Mathevet, B. Heinrich, T. Aoyama, D.-E. Kim, H. Lee, J.-C. Ribierre, C. Park, Nat. Commun. 5, 3583 (2014).
76. Y. Ji, D.F. Zeigler, D.S. Lee, H. Choi, A.K.-Y. Jen, H.C. Ko, T.-W. Kim, Nat. Commun. 4, 2707 (2013)

77. M. Takamiya, T. Sekitani, Y. Kato, H. Kawaguchi, T. Someya, T. Sakurai, IEEE J. Solid-State Circuits 42, 1 (2007)

78. J. Heikenfeld, P. Drzaic, J.-S. Yeo, T. Koch, J. Soc. Inf. Disp. 19 (2), 129 (2011).

79. D.-U. Jin, J.-S. Lee, T.-W. Kim, S.-G. An, D. Straykhilev, Y.-S. Pyo, H.-S. Kim, D.-B. Lee, Y.-G. Mo, H.-D. Kim, H.-K. Chung, SID Int. Symp. Dig. Tech. Pap. 40 (1), 983 (2009)

80. J.-S. Park, T.-W. Kim, D. Stryakhilev, J.-S. Lee, S.-G. An, Y.-S. Pyo, D.-B. Lee, Y.G. Mo, D.-U. Jin, H.K. Chung, Appl. Phys. Lett. 95, 013503 (2009).

81. K. Suzuki, K. Yutani, A. Onodera, T. Tano, H. Tomono, A. Murakami, M. Yanagisawa, K. Kameyama, Proc. IDW 16, 1581 (2009).

82. R. Matsubara, Y. Harada, K. Hatta, T. Yamamoto, M. Takei, M. Ishizaki, M. Matsumura, K. Ota, M. Ito, SID Int. Symp. Dig. Tech. Pap. 43 (1), 419 (2012). 83. T. Someya, Y. Kato, S. Iba, H. Kawaguchi, T. Sakurai, IEEE Trans. Electron Devices 52 (11), 2502 (2005)

84. Y. Kato, T. Sekitani, Y. Noguchi, T. Yokota, M. Takamiya, T. Sakurai, T. Someya, IEEE Trans. Electron Devices 57, 995 (2010).

85. H. Fuketa, K. Yoshioka, Y. Shinozuka, K. Ishida, T. Yokota, N. Matsuhisa, Y. Inoue, M. Sekino, T. Sekitani, M. Takamiya, T. Someya, T. Sakurai, IEEE Trans. Biomed. Circuits Syst. 8, 824 (2014)

86. H. Fuketa, M. Hamamatsu, T. Yokota, W. Yukita, T. Someya, T. Sekitani, M. Takamiya, T. Someya, T. Sakurai, presented at the IEEE Int. Solid-State Circuits Conf. (ISSCC) San Francisco, February 22-26, 2015; 16.4.

87. R. Libanori, R. Erb, A. Reiser, H. Ferrand, M. Süess, R. Spolenak, A. Studart, Nat. Commun. 3, 2281 (2012)

88. I. Graz, D. Cotton, A. Robinson, S. Lacour, Appl. Phys. Lett. 98, 124101 (2011).

89. J. Vanfleteren, M. Gonzalez, F. Bossuyt, Y. Hsu, T. Vervust, I. Wolf, M. Jablonski, MRS Bull. 37, 254 (2012).

90. N. Matsuhisa, M. Kaltenbrunner, T. Yokota, H. Jinno, K. Kuribara, T. Sekitani, T. Someya, Nat. Commun. 6, 8461 (2015).

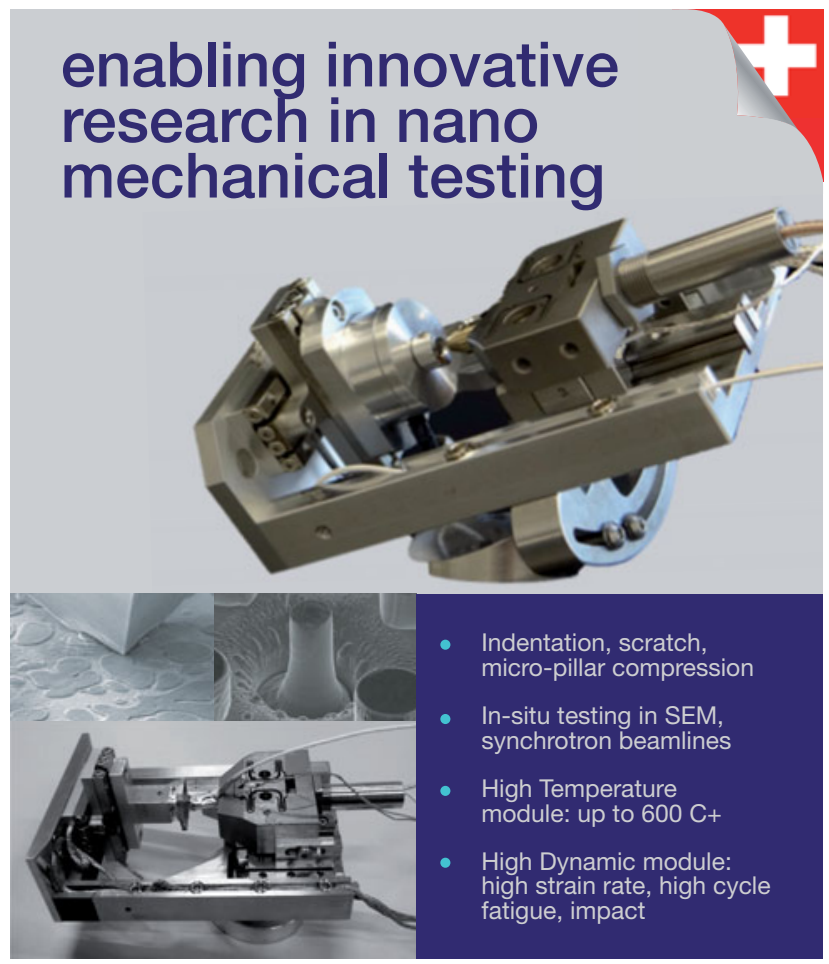

Feuerwerkerstr. 39 3602 Thun, Switzerland T: +41335349757

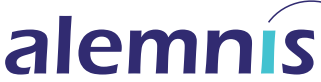
www.alemnis.ch 